\title{
Evaluation of larvicidal properties of the latex of Euphorbia tirucalli L. (Euphorbiaceae) against larvae of Anopheles mosquitoes
}

\author{
Julius Mwine ${ }^{1 \star}$, Patrick Van Damme ${ }^{2}$ and Francis Jumba ${ }^{1}$ \\ ${ }^{1}$ Faculty of Agriculture, Uganda Martyrs University, Nkozi, P. O. Box 5498, Kampala, Uganda. \\ ${ }^{2}$ Faculty of Bioscience Engineering, Tropical and subtropical laboratory of Agronomy and Ethnobotany, University of \\ Ghent, Coupure links 653, 9000 Ghent, Belgium.
}

Accepted 30 August, 2010

\begin{abstract}
Malaria is the most important vector-borne disease in tropical and sub-tropical countries. Although, different control measures like use of insecticide-impregnated mosquito nets and curtains, chemotherapy and others are in place, so far, malaria eradication has proved impossible in affected areas. Therefore, any measure that attempts to fight the parasite or its vector (Anopheles spp.) would be of help. In this experiment, we assessed the efficacy of Euphorbia tirucalli latex both as a herbal mosquito remedy and larvicide against Anopheles fenestus Giles and Anopheles gambae Giles in a semi-natural environment. Our results indicate that $E$. tirucalli latex can bring about total mortality of Anopheles species larvae at the highest dilution used of 1: 250 in 5 days. LT 50 and LT 90 for the same dilution were attained at 12 and $36 \mathrm{~h}$ respectively. Latex was active only for eight days which is typical for herbal biocides, whose advantage is that they do not accumulate in the environment. It is concluded that $E$. tirucalli latex has a high efficacy against Anopheles mosquito larvae and could eventually be considered for adoption as a plant based mosquito larvicide, after further research.
\end{abstract}

Key words: Euphorbia tirucalli, Anopheles spp., latex, larvicide, malaria, efficacy.

\section{INTRODUCTION}

Malaria is the most important vector-borne disease in the tropics and sub-tropics (Komisar, 2007; Stratton, 2008). WHO (www.who.int/whosis) reports that malaria affects over 100 countries and approximately $40 \%$ of the world's population, killing about one million people annually. Africa is reported to be the most affected continent and every one of five childhood deaths is due to the disease.

Corresponding author. E-mail: mwinej@yahoo.com.
Those who survive usually suffer from malarial after-effects like slow growth, learning impairment and sometimes general disability (Carter et al., 2005; Urbach, 2008). In Uganda alone, malaria accounts for 25 to $40 \%$ of all visits at health care facilities and over $20 \%$ of all hospital admissions. The disease is responsible for death of 70,000 to 100,000 children under 5 years annually (www.go.ug/malaria.htm). According to the latter source, average households spend about $25 \%$ of their income on malaria while sub-Saharan governments spend about $40 \%$ of their health budgets on malarial-related activities. 
The international community has attempted to provide help by setting up such assistance facilities as the Global Fund for HIV- AIDS, tuberculosis and malaria to check incidences of these diseases (Wendo, 2003; Atun and Kazatchkine, 2010).

A number of measures to control malaria have been put in place since the discovery of quinine from the cinchona tree (Cinchona officinalis L., Rubiaceae). Although, chemotherapy remains the most important method to combat malaria, frantic efforts have been devised to fight it at different levels, for example at vector level by killing mosquitoes or preventing them from reaching their prey (Goodman et al., 1999). In Uganda, this has been done using different methodologies such as environmental management, spraying walls that act as mosquito resting places, use of insecticide- impregnated mosquito nets and curtains among others (Kilian et al., 2008; Rubaihayo et al., 2009; Pullan et al., 2010). To enhance present control measures, indoor spraying with DDT (which was banned in many countries) has been coopted by the Uganda government possibly for lack of better alternatives (Bimenya et al., 2010). Elimination or killing of mosquitoes is one of the most commonly used methods of fighting malaria (Killeen et al., 2002b). Mosquitoes can be attacked at different developmental stages including egg, larval and adult stages. During larval stages, mosquitoes are active and aquatic. This puts them at a disadvantage as their mobility is limited to water bodies where both food and air for gaseous exchange are obtained, making them susceptible to any changes that occur in the water body (Killeen et al., 2002a). This weakness can be used against larvae, which can be attacked by blocking food supply, breathing systems or both.

The use of larvicides is one of the oldest methods of controlling malaria (Killeen et al., 2002b). Among other advantages, use of larvicides controls mosquitoes before they are able to spread and transmit diseases (Fillinger et al., 2003; Killeen et al., 2002a). While other methods like adult spraying may have direct effects like visible protection of populations and may show quick results, larval control has yielded several success stories where malaria has been brought under control, including in countries such as Brazil, Egypt and Zambia (Killeen et al., 2002b). According to these authors, use of larval control methods was abandoned after the discovery of DDT, which was used as an adult spray and was seen as a panacea to all insect problems.

Due to the disadvantages associated with such synthetic pesticides, including development of pesticide resistant strains, ecological imbalances and harm to nontarget organisms, there is a renewed effort to develop substances of plant origin which are considered to be more environmentally friendly due to their innate biodegradability and lower toxicity to most organisms (Frederich et al., 2002).
Several researchers have investigated the application of plant extracts to fight malaria vectors. Plant species cited in literature for this purpose include Achyranthus aspera (Bagavan et al., 2008) Azadirachta indica (Aliero, 2003), Jatropha curcas, Euphorbia tirucalli, Euphorbia hirta, Phyllanthus amarus and Pedilanthus tithymaloides (Rahuman et al., 2008a), Piper nigrum (Rasheed et al., 2005), Chenopodium album (Sharma et al., 2006), Solanum xanthocarpum (Mohan et al., 2005), Ajuga remota (Sharma et al., 2004), Thymus capitatus (Mansour et al., 2000), Tagetes erectes, Cleome icosandra, Ageratum conyzoides, Eichhornia crassipes (Saxena et al., 1992) among others. These authors have validated and independently reported on chemical substances like flavonoids, diterpenoids, triterpenoids, esters and alkaloids among others, in respective plant tissues and their degree of anti-malarial efficacy.

In this paper, we focused on assessing the larvicidal properties of $E$. tirucalli $L$ (Euphorbiaceae) against Anopheles mosquitoes. E. tirucalli is a small tree that grows $3-6 \mathrm{~m}$ tall and has pencil-like branches. Therefore, it is commonly referred to as the pencil tree (English), or Utupa or mtupa (Swahili), and in some Ugandan dialects, Oruyenje (Runyankole) and Kakoni (Luganda). The tree is typically used as a fence plant and for boundary demarcation since it is not braised by domestic animals, has few pests and is not easily destroyed by hardier conditions like drought and salt stress (Van, 2001). Like many other Euphorbiaceae, E. tirucalli is a well known medicinal plant both locally and internationally. It is reported to have curative features for a number of diseases.

In Africa, it is said to cure snakebites, warts, sexual impotence, and syphilis and to extract skin parasites. In Asia, it is popular for treating broken bones, hemorrhoids, pains, warts, swellings and ulcerations. In Brazil, the list is even longer including the above in addition to scorpion bites, asthma, cancer, spasms and others (Cataluna and Rates, 1997; Van, 2001). Available literature also shows that E. tirucalli has larvicidal (Rahuman et al., 2008a; Yadav et al., 2002), anti-fungal (Mohamed et al., 1996), piscicidal (Neuwinger, 2004), anti-viral (Betancur-Galvis et al., 2002) as well as anti-bacterial (Lirio et al., 1998) features. Petroleum extracts of $E$. tirucalli have been tested against Aedes aegypti and Curex quinquefasciatus and were found potent enough to cause larval mortality for $A$. aegypti and $C$. quinquefasciatus (LC $50=4.25$ and 5.52 ppm, respectively; Rahuman et al., 2008a). Having shown a high larvicidal efficacy against Aedes and Curex spp, this study hypothesized that the same potency could be shown against Anopheles species. The present study was therefore designed to investigate whether latex of $E$. tirucalli has enough potency to cause harm or kill Anopheles mosquito larvae in their semi-natural environment so as to be adopted for use as a mosquito control measure. 


\section{MATERIALS AND METHODS}

\section{Experimental site}

The experiment was set up in a swampy area at Kajansi $\left(0^{\circ} 13^{\prime} 09\right.$ $58^{\prime \prime} \mathrm{N} ; 32^{\circ} 32^{\prime} 0318^{\prime \prime}$ E) about $10 \mathrm{~km}$ from Kampala city, central Uganda. A neglected fish pond belonging to National Agricultural Research Organization originally used by Kajansi Fisheries Research Development Center to breed fish was used. The pond was 28 by $19 \mathrm{~m}$ in size and $1.2 \mathrm{~m}$ deep when it was active. At experiment time, it contained shallow rainwater, which was about $0.2 \mathrm{~m}$ in depth.

\section{Experimental design}

The present experiment was designed following Fillinger et al. (2003) with a few modifications. Sixteen plastic tubs, each with a diameter of $0.5 \mathrm{~m}$, were buried in a neglected pond to a depth of $0.4 \mathrm{~m}$. Tubs were arranged in the pond in four rows and four columns with a distance of $2 \mathrm{~m}$ in between. All tubs were provided with approximately $6 \mathrm{~kg}$ of top soil drawn from the experimental area to provide normal abiotic and biotic conditions to mosquitoes. They were then filled with tap water and maintained at a depth of about $0.4 \mathrm{~m}$ with a provision of overflow holes to allow excess water leave the tubs in case of rain. A nylon net meshing was provided at overflow holes to stop mosquito larvae from escaping with excess water. Tubs were left open to allow oviposition. Water temperatures during the experiments ranged between a minimum of $16^{\circ} \mathrm{C}$ and a maximum of $38^{\circ} \mathrm{C}$. The experiment was carried out during November 2008 (rainy season) and repeated in March 2009 (dry season).

\section{Euphorbia tirucalli extract}

E. tirucalli latex used was locally obtained by making incisions on mature branches of trees from which latex oozed into small sample bottles. Sample bottles were corked and wrapped with aluminum foil to stop latex solarization that would make it deteriorate (OliveiraFilho EC and Paumgartten, 1997). Bottles were put in a cooler (icebox) and kept at about $4^{\circ} \mathrm{C}$ to stop coagulation until experimental time.

\section{Experimental mosquitoes}

Our preliminary studies (unpublished) revealed that dominant Anopheles species at the experimental site (neglected fish pond) were Anopheles funestus and $A$ gambae in a ratio of $1: 3$ for $A$. gambae and $A$. funestus respectively. During this particular study, experimental mosquitoes were identified with the help of senior entomologist at vector control division, Kampala. Mosquitoes assessed were those found naturally breeding in the area in order to approximate to a semi-natural environment.

\section{Experimental assay}

Following our preliminary experiments carried out at Department of Vector Control in Wandegeya, Kampala on lethal dose (Mwine, unpublished), the following latex dilutions were used: 1:250, 1:200 and 1:150 of fresh latex to water (volume by volume) whereas the control was treated with tap water. These initial dilutions were obtained by mixing appropriate quantities of latex with $1 \mathrm{~L}$ of water drawn from respective experimental tubs. A randomized complete block design was used in experimental setup and each treatment was replicated four times. Before treatment with each respective dilution, the set up was left to stand for eight days to allow oviposition and emergence of a good number of larvae to ease the sampling process (Fillinger et al., 2003). Following the methodology of the same author, sampling for mosquito larvae to establish their presence, taxonomic characteristics and stage of development (before treatment) was carried out using a $350 \mathrm{ml}$ dipper at different sides of tubs. Four dips per tub were taken for this initial test.

\section{Sampling and assessment}

Sampling of larvae was carried out at $0,12,24$ and $36 \mathrm{~h}$ and then on a daily basis for 15 days using the same technique as for the initial test. Sampling was sequenced in such a way that replicates of similar dilution were sampled consecutively with the same dipper. One dip was taken from each tub at a time, returning to it later, on completion of the cycle for that particular treatment until all four samples were taken. This was done to allow diving larvae return to the surface for equal chances of being sampled (Fillinger et al., 2003). Larvae sampled were observed for livelihood by touching them with a seeker. Both dead and living larvae were recorded and returned to their respective tubs but pupae were removed and disposed of to minimize emergence of adults. Tubs were checked twice a day for this purpose (Fillinger et al., 2003).

\section{Data analysis}

Treatment means of larvae and pupae found alive after treatment were calculated and subjected to Kruskal-Wallis one-way analysis of variance by ranks test ( $\mathrm{H}$ test) to determine if there was a significant difference in population trends. Individual means were compared between one another using Mann-Whitney $U$ test to establish significant differences between treatments and the control. Results with $\mathrm{P} \leq 0.05 \%$ were considered statistically significant. Percentage mortality was calculated using the formula of Mulla et al.; (1971) which takes into account natural factors of population change in an ecosystem. Mortality $=100-(\mathrm{C} 1 / \mathrm{T} 1$ $x T 2 / C 2) x 100$, where $C 1$ and $C 2$ represent average numbers of larvae in control tubs pre- and post-treatment respectively, and T1 and T2 for tubs treated with experimental formulations, pre- and post-treatment respectively. Mortalities less than zero were corrected to zero. Microsoft Excel for Windows 2007 was used for performing calculations.

\section{RESULTS}

A high efficacy against Anopheles mosquito larvae was returned by all $E$. tirucalli treatments unlike the control as shown on Figure 1. A statistical comparison of treatments means after mortality peak (day 10 after treatment) reveals that there is a significant difference between effectiveness of different treatments $(H=12.17$, df $=3, P$ $=0.007)$. A post-test comparison of treatment means (compared with control) using a Mann-Whitney $U$ test reveals that latex treatment samples were significantly different from the control $(T 1: U=11.27, P=0.0008$; $T 2$ : 


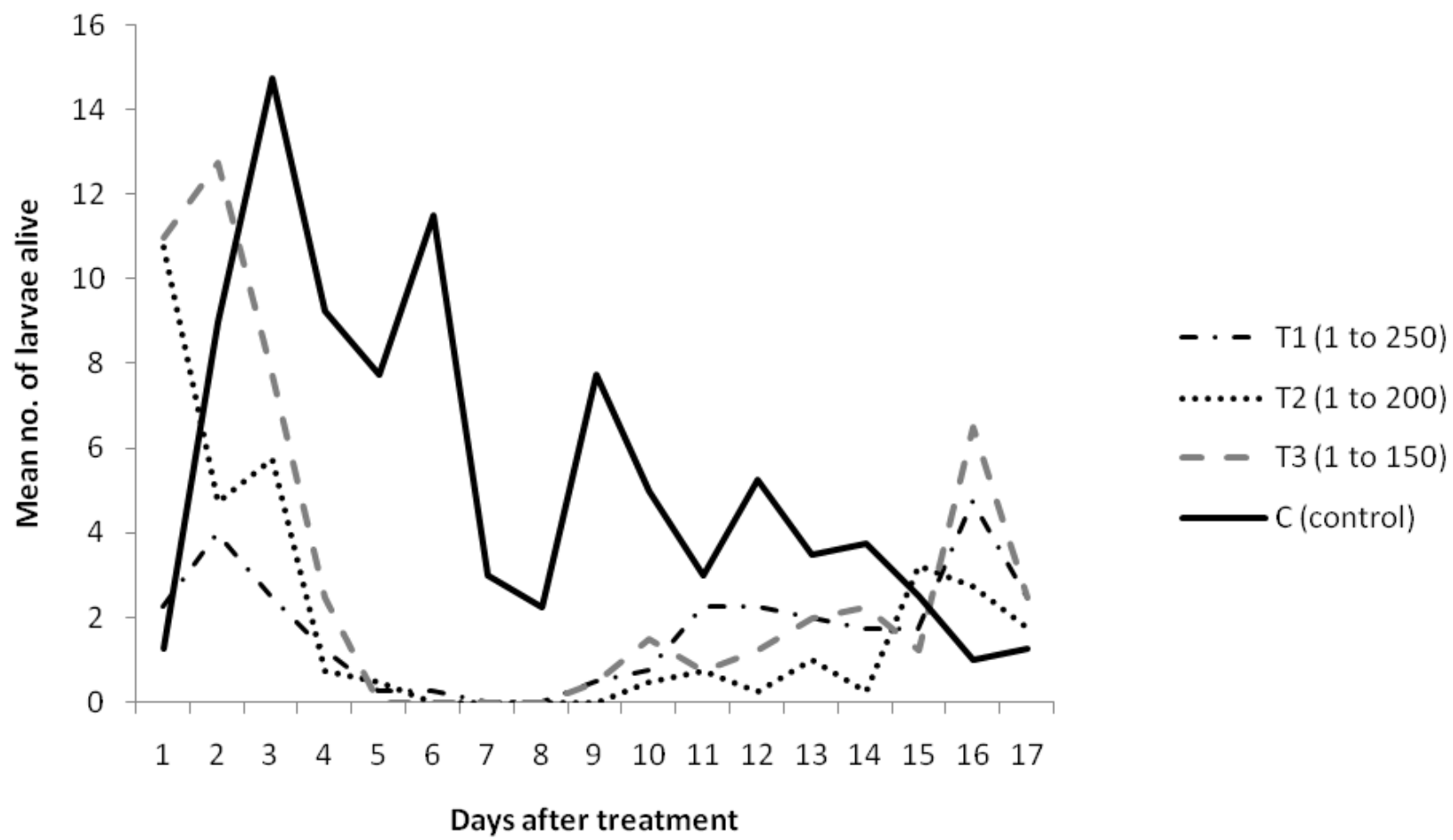

Figure 1. Means of Anopheles spp larvae alive after treatment with E. tirucalli latex.

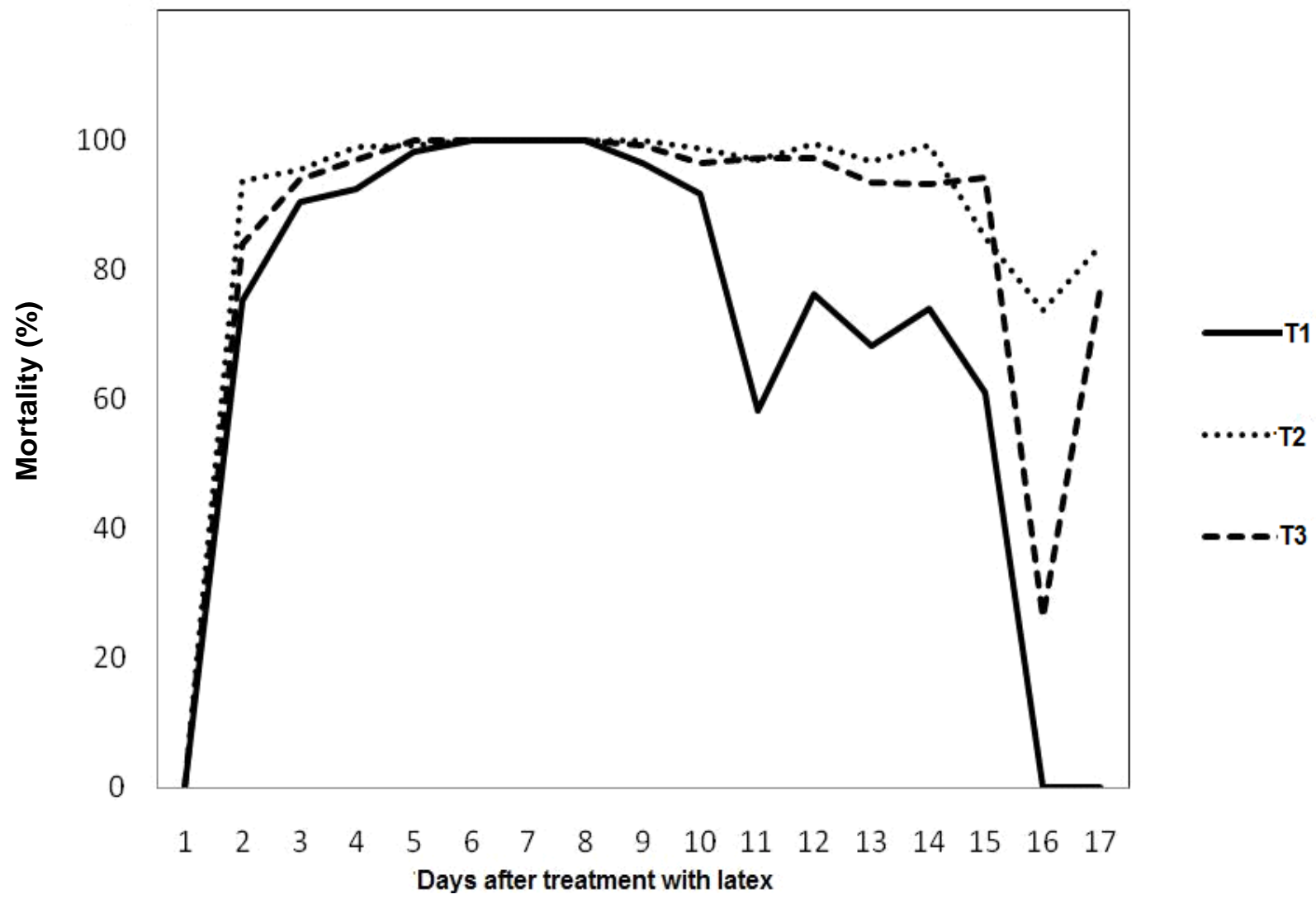

Figure 2. Larval mean mortality in the treatments. 
$U=7.85, P=0.005 ; \mathrm{T} 3: \mathrm{U}=4.59, \mathrm{P}=0.032$ ). Our assumption (null hypothesis) of uniform efficacy for the treatments and control is rejected. Calculated larval mortality also revealed a high efficacy for all three latex treatments. LT 50 and LT 90 were reached within 12 and $36 \mathrm{~h}$ of application respectively, for the highest dilution $(T 1=1: 250)$ attaining total mortality in 5 days (Figure 2). Latex appeared effective between day two and day eight after treatment, as numbers of mosquito larvae alive were diminishing during this period but started rising again after the eighth day in all treatments.

\section{DISCUSSION}

Use of larvicidals against mosquitoes is an old method of malarial control (Fillinger et al., 2003) and has of late been brought back on the market due to need of alternatives from harmful sprays (Bagavan et al., 2009; Kamaraj et al., 2009). Along the same line, the revival of research on plant-based pesticides over the last few decades responds to recognition of a need to replace harmful, non-selective and environmentally unfriendly synthetic pesticides some of which have already been internationally banned. Our results indicate that $E$. tirucalli latex has a high efficacy against Anopheles mosquito larvae. Figure 2 shows that at a dilution as low as 1: 200, fresh latex was able to cause $80 \%$ larval mortality in only $12 \mathrm{~h}$ rising to $100 \%$ in $4-5$ days. Of the dilutions tested (Figure 1) all three attained LT50 within $12 \mathrm{~h}$ and LT 90 in $36 \mathrm{~h}$. This indicates that, in analogy with most crude plant extracts (Mullai and Jebanesan, 2007; Rahuman et al., 2009; Yenesew et al., 2003), E. tirucalli latex does not have a knockdown effect but displays a steady killing rate and high efficacy against Anopheles mosquito larvae. Results also show that fresh E. tirucalli latex is active for a short time. Figures 1 and 2 indicate that larval mortality peaks between day five and eight after application and starts decreasing thereafter. This is a typical response of plant based pesticides which generally do not persist in the environment. However, the disadvantage is that one has to apply them frequently in order to bring down pest levels. Since all three dilutions tested have sufficient potency to kill mosquito larvae within 4 days, the lowest dilution can be recommended for application so as to avoid usage of heavy doses which may bring about problems. After all, E-tirucalli is known to be toxic (Furstenberger and Hecker, 1977; Shlamovitz et al., 2009) and has been pointed out to be co-carcinogenic (Furstenberger and Hecker, 1985; Liu et al., 1998; MacNeil et al., 2003). Therefore, lower dilutions are to be preferred. However, there are indications that much lower doses may not have similar efficacy as we found out in our preliminary trials that dilutions lower than 1:250 do not return good results. Results from the present study are not a surprise since Euphorbiaceae plants are known to possess chemical substances like triterpenes (Khan et al., 1988; Rahuman et al., 2008b; Rasool et al., 1989), diterpenes (Khan and Malik, 1990; Marco et al., 1997) rotenoides (Yenesew et al., 2003), saponins (Bagavan et al., 2008), tannins (Yoshida et al., 1991) flavonoids and alkaloids, among others, which have been found to have reasonable efficacy against a range of mosquito species. Rahuman (2008a) and Yadav et al. (2002) tested E. tirucalli latex against Culex spp and Aedes spp, albeit in extracted form and established similarly high efficacies as in the present experiment. To the best of our knowledge, this is the first report on evaluation of $E$. tirucalli latex against Anopheles spp. Results of extraction and purification of active compounds in E. tirucalli latex will be published elsewhere.

\section{Conclusions}

The present study has demonstrated that fresh $E$. tirucalli latex has a reasonably high efficacy to cause mortality in Anopheles spp larvae. Since all tested dilutions can return LT 90 within $36 \mathrm{~h}$, our interest should focus on the highest dilution (1: 250) to minimize excess latex usage and thus avoid spoilage but also minimize problems and risks associated with overdosing. According to our results, latex is most active in only five days. It is therefore logical, to apply it twice weekly to maintain an active dose in the environment during the period of high larval incidence. During periods of low larval incidence, a single application once a week should suffice. It should be noted that while we recommend local people to continue spraying $E$. tirucalli latex as a larvicide, extended use and commercialization should await further research, which may include extraction and purification of active ingredients.

\section{REFERENCES}

Aliero BL (2003). Larvaecidal effects of aqueous extracts of Azadirachta indica (neem) on the larvae of Anopheles mosquito. Afr. J. Biotechnol., 2: 325-327.

Atun R, Kazatchkine M (2010). The Global Fund's leadership on harm reduction: 2002-2009. Int. J. Drug Polic., 21: 103-106.

Bagavan A, Rahuman A A, Kamaraj C, Geetha K (2008). Larvicidal activity of saponin from Achyranthes aspera against Aedes aegypt and Culex quinquefasciatus (Diptera: Culicidae). Parasitol. Res., 103: 223-229.

Bagavan A, Kamaraj C, Rahuman A A, Elango G, Zahir AA, Pandiyan G (2009). Evaluation of larvicidal and nymphicidal potential of plant extracts against Anopheles subpictus Grassi, Culex tritaeniorhynchus Giles and Aphis gossypii Glover. Parasitol. Res., 104: 1109-1117.

Betancur-Galvis LA, Morales GE, Forero JE, Roldan J (2002). Cytotoxic and antiviral activities of Colombian medicinal plant extracts of the Euphorbia genus. Mem. Institut. Oswaldo Cruz, 97: 541-546.

Bimenya GS, Harabulema M, Okot JP, Francis O, Lugemwa M, Okwi AL (2010). Plasma levels of DDE/DDT and liver function in malaria control personnel 6 months after indoor residual spraying with DDT in Northern Uganda. S. Afr. Med. J., 100: 118-121. 
Carter JA, Mung'ala-Odera V, Neville BGR, Murira G, Mturi N, Musumba N, Newton CR (2005). Persistent neurocognitive impairments associated with severe falciparum malaria in Kenyan children. J. Neurol. Neurosurg. Psychiatry, 76: 476-481.

Cataluña P, Rates SMK (1997). The traditional use of the latex from Euphorbia tirucalli $\mathrm{L}$ (Euphorbiaceae) in the treatment of cancer in south Brazil. ISHS Acta Hort., 50: 1-14.

Fillinger U, Knols BGJ, Becker N (2003). Efficacy and efficiency of new Bacillus thuringiensis var. Israelensis and Bacillus sphaericus formulations against Afro-tropical Anophelines in Western Kenya. Trop. Med. Int. Health, 8: 37-47.

Frédérich M, Dogné JM, Angenot L, De Mol P (2002). New trends in anti-Malarial agents. Curr. Med. Chem., 9: 1435-1456.

Furstenberger G, Hecker E (1977). New highly irritant Euphorbia factors from latex of Euphorbia tirucalli L. Experientia, 33: 986-988.

Furstenberger G, Hecker E (1985). On the active principles of the spurge family (Euphorbiacea) 11: The skin irritant and tumor promoting diterpene esters of Euphorbia tirucalli $\mathrm{L}$ originating from south Africa. J. Biosci., 40: 631-646.

Goodman CA, Coleman PG, Mills AJ (1999). Cost-effectiveness of malaria control in sub-Saharan Africa. Lancet, 354: 378-85.

Kamaraj C, Bagavan A, Rahuman AA, Zahir AA, Elango G, Pandiyan G (2009). Larvicidal potential of medicinal plant extracts against Anopheles subpictus Grassi and Culex tritaeniorhynchus Giles (Diptera: Culicidae). Parasitol. Res., 104: 1163-1171.

Khan AQ, Malik A (1990). A new macrocyclic diterpene ester from the latex of Euphorbia tirucalli. J. Nat. Prod., 53:728-731.

Khan AQ, Rasheed T, Kazmi SN, Ahmed Z, Malik A (1988). Cycloeuphordenol, a new triterpene from Euphorbia tirucalli. Phytochem., 27: 2279-2281.

Kilian A, Byamukama W, Pigeon O, Atieli F, Duchon S, Phan C (2008). Long-term field performance of a polyester-based long-lasting insecticidal mosquito net in rural Uganda. Malar. J., 7: 49.

Killeen G, Fillinger U, Knols B (2002). Advantages of larval control for African malaria vectors: Low mobility and behavioural responsiveness of immature mosquito stages allow high effective coverage. Malar. J., 1:8

Killeen GF, Fillinger U, Kiche I, Gouagna LC, Knols BGJ (2002). Eradication of Anopheles gambiae from Brazil: Lessons for malaria control in Africa? Lancet Infect. Dis., 2: 618-627.

Komisar JL (2007). Malaria vaccines. Front. Biosci. 12: 3928-3955.

Lirio LG, Hermano ML, Fontanilla MQ (1998). Antibacterial activity of medicinal plants from the Philippines. Pharm. Biol., 36: 357-359.

Liu ZS, Liu YF, Zeng Y (1998). Synergistic effect of Epstein-Barr virus and tumor promoters on induction of lymphoma and carcinoma in nude mice. J. Cancer Res. Clin. Oncol., 124: 541-548.

MacNeil A, Sumba OP, Lutzke ML, Moormann A, Rochford R (2003). Activation of the Epstein-Barr virus lytic cycle by the latex of the plant Euphorbia tirucalli. Br. J., Cancer, 88: 1566-1569.

Mansour S, Messeha SS, el-Gengaihi SA (2000). Botanical biocides 4: Mosquitocidal activity of certain Thymus capitatus constituents. J. Nat. Toxins., 9: 49-62.

Marco JA, Sanzcervera JF, Yuste A (1997). Ingenane and lathyrane diterpenes from the latex of Euphorbia canariensis. Phytochem., 45: 563-570.

Mohamed S, Saka S, Elsharkawy SH, Ali AM, Muid S (1996). Antimycotic screening of 58 Malaysian plants against plant pathogens. Pestic. Sci., 47: 259-264.

Mohan L, Sharma P, Srivastava CN (2005). Evaluation of Solunum xanthocarpum extracts as mosquito larvicides. J. Environ. Biol., 26: 399-401.

Mulla MS, Norland RL, Fanara DM, Darwazeh HA, McKean DW (1971). Control of chironomid midges in recreational lakes. J. Econ. Entomol., 64: 300-307.

Mullai K, Jebanesan A (2007). Larvicidal, ovicidal and repellent activities of the leaf extract of two cucurbitacious plants against filarial vector Culex quinquefasciatus (Say) (Diptera: Culicidae). Trop. Biomed., 24: 1-6.

Neuwinger HD (2004). Plants used for poison fishing in tropical Africa. Toxicon., 44: 417-430.
Oliveira-Filho EC, Paumgartten F (1997). Photodegradation of the Molluscicidal Latex of "Crown-of-Thorns" (Euphorbia milii var hislopii) Mem. Inst. Oswaldo Cruz, 92: 657-659.

Rahuman A, Gopalakrishnan G, Vankatesan P, Kannappan G (2008). Larvicidal activity of some Euphorbiaceae plant extracts against Aedes aegypti and Curex quinquefasciatus (Diptera: Culicidae). Parasitol. Res., 102: 867-873.

Rahuman AA, Venkatesan P, Geetha K, Gopalakrishnan G, Bagavan A, Kamaraj C (2008). Mosquito larvicidal activity of gluanol acetate, a tetracyclic triterpenes derived from Ficus racemosa Linn. Parasitol. Res., 103: 333-339.

Rahuman AA, Bagavan A, Kamaraj C, Vadivelu M, Zahir AA, Elango G, Pandiyan G (2009). Evaluation of indigenous plant extracts against larvae of Culex quinquefasciatus Say (Diptera: Culicidae). Parasitol. Res., 104: 637-643.

Rasheed M, Afshan F, Tariq RM, Saddiqui SB, Gulzar T, Mahmood A, Begum S, Khan B (2005). Phytochemical studies on the seed extract of Piper nigrum Linn. Nat. Prod. Res., 19: 703-712.

Rasool N, Khan AQ, Malik A (1989). A taraxerane type triterpene from Euphorbia tirucalli. Phytochem., 28: 1193-1195.

Rubaihayo J, Tukesiga E, Abaasa A (2009). Reduced susceptibility to pyrethroid insecticide treated nets by the malaria vector Anopheles gambiae s.I. in western Uganda. Malar. J., 7: 92.

Saxena RC, Dixit OP, Sukumaran P (1992). Laboratory assessment of indigenous plant extracts for anti juvenile hormone activity in Culex quinquefusciatus. Indian J. Med. Res., 95: 204-206.

Sharma P, Mohan L, Srivastava C (2004). Larval suseptability of Ajuga remota against Anophelene and Curicine mosquitoes. Southeast Asian J. Trop. Med. Public Health. 35: 608-610.

Sharma P, Mohan L, Srivastava CN (2006). Phytoextract induced developmental deformities in malaria vector. Bioresour. Technol., 97: 1599-1604.

Shlamovitz GZ, Gupta M, Diaz JA (2009). A case of acute keratoconjunctivitis from exposure to latex of Euphorbia tirucalli (pencil cactus). J. Emer. Med., 36: 239-241.

Stratton L, O'Neill MS, Kruk ME, Bell MB (2008). The persistent problem of malaria: Addressing the fundamental causes of a global killer. Soc. Sci. Med., 67: 854-862.

Urbach J (2008). Malaria takes toll on African economies. Afr. Exec., 20: 27.

Van Damme PLJ (2001). Euphorbia tirucalli for high biomass production. In: Schlissel A, Pasternak D(Eds) Combating desertification with plants, Kluwer Academic Publishers, pp. 169-187.

Wendo C (2003). Uganda agrees to increase health spending using Global Fund's grant. Lancet, 361: 319-319.

Yadav R, Srivastav K, Ramesh C, Singh A (2002). Larvicidal activity of latex and stem bark of Euphorbia tirucalli plant on the mosquito culex quinquefasciatus. J. Comm. Dis., 34: 264-269.

Yenesew A, Derese S, Midiwo JO, Heydenreich M, Peter MG (2003). Effect of rotenoids from the seeds of Millettia dura on larvae of Aedes aegypti. Pest Manag. Sci., 59: 1159-1161.

Yoshida T, Yokoyama K, Namba O, Okuda T (1991). Tannins and related polyphenols of Euphorbiaceous plants: 7 tirucallin-a, tirucallin$\mathrm{b}$ and euphorbin-f, monomeric and dimeric ellagitannins from Euphorbia tirucalli L. Chem. Pharm. Bull., 39: 1137-1143. 